\title{
A research view of supply chain management: Developments and topics for exploration
}

\author{
James R Stock*
}

Received: 11 August 2009; Revised: 16 September 2009; Accepted: 28 September 2009

\begin{abstract}
There have been advances in the understanding of supply chain management (SCM) since its inception in the early-1980s. However, there are still some basic issues of SCM that remain unresolved. Much of the research that has been conducted takes one or more of the following three perspectives: (1) development of methods and techniques to study SCM and its components/processes; (2) developing solutions or answers to specific supply chainrelated problems or challenges; and/or (3) measuring the results or outcomes of supply chain strategies and tactics. Each of these three perspectives is briefly examined, with selected examples from the literature cited to illustrate the type of research that has been conducted. Some potential areas of research exploration are presented. The areas examined include: theory development, and SCM processes and functions.
\end{abstract}

Key words: Modelling, quantitative research, simulation, structural equation modelling (SEM), supply chain management, theory.

\section{Introduction}

The term "supply chain management" (SCM) is believed by most researchers to be first introduced in written form by Keith Oliver, a management consultant at Booz Allen Hamilton, as reported in the Financial Times in 1982 (Laseter and Oliver, 2003). Since that time, thousands of articles and books have been published on the topic. Certainly, SCM is now "front-and-center" with respect to implementing national and international business strategies.

The number of SCM-related periodicals has grown considerably since the introduction of SCM. Menachof et al. (2009) identified 82 periodicals that have published SCM-related articles and case studies. However, even though the numbers of periodicals and articles have increased, that is not to say that from a theoretical standpoint, SCM has made similar advances. Undoubtedly, there have been advances in the understanding of the supply chain field generally, and in the specific components and processes that make up

\footnotetext{
${ }^{*}$ Department of Marketing, College of Business, University of South Florida, 4202 East Fowler Avenue,
} Tampa, Florida, email: jstock@coba.usf.edu 
the field. However, there are still some basic issues that remain unresolved, and which are important topics for researchers and scholars investigating the field.

For example, while SCM has been around for $25+$ years, there is still no consensus definition of the field and what it entails. Probably the most widely held view of SCM is that espoused by the Council of Supply Chain Management Professionals (CSCMP). They define SCM as follows:

"SCM encompasses the planning and management of all activities involved in sourcing and procurement, conversion, and all Logistics Management activities. Importantly, it also includes coordination and collaboration with channel partners, which can be suppliers, intermediaries, third-party service providers, and customers. In essence, Supply Chain Management integrates supply and demand management within and across companies" (CSCMP, 2009).

CSCMP also provides a brief description of the boundaries of SCM which includes "primary responsibility for linking major business functions and business processes within and across companies into a cohesive and high-performing business model. It includes all of the Logistics Management activities noted above, as well as manufacturing operations, and it drives coordination of processes and activities with and across marketing, sales, product design, finance and information technology" (CSCMP, 2009).

Most recently, Stock and Boyer (2009) have developed a consensus definition of SCM by performing a qualitative analysis of 173 unique definitions of the field, collected from articles and books published on the subject from 1985 through 2008. Their definition, which is perhaps the most comprehensive, since it is based on the qualitative analysis of an extensive literature review, is as follows:

"The management of a network of relationships within a firm and between interdependent organizations and business units consisting of material suppliers, purchasing, production facilities, logistics, marketing, and related systems that facilitate the forward and reverse flow of materials, services, finances and information from the original producer to final customer, with the benefits of adding value, maximizing profitability through efficiencies, and achieving customer satisfaction" (Stock and Boyer, 2009).

For SCM theory development, constructs must be defined specifically (Hunt, 1976). Researchers will have to arrive at a consensus definition of SCM so that the discipline may move forward with the development of SCM theories and sub-theories.

When examining the published SCM literature, researchers from disciplines such as logistics, operations research, management, organisational behaviour, and industrial engineering, have published the bulk of articles appearing in SCM-related journals. Typically, however, each of the disciplines applies their own specific approaches, methodologies, and priorities to SCM. There are few studies that take a multi-disciplinary perspective. While there is nothing inherently wrong with taking specific approaches to studying SCM, the field only advances incrementally, rather than seeing significant advances like those found 
when processes are reengineered. For example, logistics researchers tend to examine transportation, warehousing, 3PL, inventory management, and similar logistics-related topics within the supply chain. Operations researchers and industrial engineers utilize mathematical techniques, simulation and modelling, and a systems approach, in studying SCMrelated topics. Management and organisational behaviour researchers tend to concentrate on behavioural issues, strategic partnerships and alliances, supply chain coordination, and collaboration between supply chain members. Again, these areas are important aspects of SCM for researchers to investigate. However, much more can be accomplished that will advance the field, as will be discussed in the sections that follow.

In the following pages, several topics relating to the present and future development of the SCM discipline are presented and briefly discussed. They include a more specific examination of the issue of theory development, the use of qualitative and quantitative methodologies to examine SCM-related topics, and several specific topics that are fertile areas for SCM researchers to explore. The majority of the references cited in this article are from the period 2000 to 2009. This is not to say that advances in SCM theory and practice

did not occur earlier. However, it would be impossible to cover the entire spectrum of SCM-related literature, and so it was decided to concentrate primarily on newer citations, with the exception that some key earlier works are cited as necessary.

\section{Developments}

When one examines the many academic journals that publish SCM-related articles, case studies and the like, it appears that much of the research being conducted takes one or more of the following three perspectives: (1) development of methods and techniques to study SCM and its components/processes; (2) developing solutions or answers to specific supply chain-related problems or challenges; and/or (3) measuring the results or outcomes of supply chain strategies and tactics. Each of these three perspectives is examined in the following sections, with selected examples from the literature cited to illustrate the type of research that has been conducted.

\subsection{Development of methods and techniques to study SCM and its components/processes}

As evidenced by the multiplicity of SCM definitions that exist, the discipline includes a number of functions and processes. To provide some structure to the large number of supply chain components, Charvet et al. (2008) employed bibliometrics, which is the mathematical and statistical analysis of written material, to examine the published SCM literature in order to develop a more simplified structure. Employing multidimensional scaling, the authors identified four areas of SCM-related research development, including logistics-related, operations research-related, interorganisational relationships and strategic alliances, and a "potpourri" of miscellaneous topics. They commented that much of the research on SCM has been conducted independently and is, therefore, not correlated. This results in a lack of research synergy.

One researcher has commented on the dichotomy that has developed between operations 
research and SCM (Dooley, 2009). Dooley (2009) stated that SCM research is divided into two major groups: analytical modelling and empirical work. The author made an interesting observation relating to how the Journal of Operations Management (JOM) was created in 1980 with the purpose of giving "high priority ... to papers reporting on actual application of proposed theories or concepts in an organization" (Boyer and Swink, 2006, p. 732). Sanders (2009) reinforced the notion that there were methodological differences in how researchers approach SCM topics. She argued that a combination of methodologies and approaches would best serve the needs of researchers investigating SCM. Because SCM is boundary-spanning, so too must be the methodologies that are used to explore it.

About one-quarter of all manuscript submissions to, and articles published in, the Journal of Business Logistics between 2006 and 2009 were quantitative-oriented manuscripts. Giunipero et al. (2008) examined 405 articles published from 1997 to 2006 in nine SCM-related journals (Decision Sciences, Industrial Marketing Management, International Journal of Physical Distribution \& Logistics Management, The International Journal of Logistics, International Journal of Operations and Production Management, Journal of Business Logistics, Journal of Operations Management; Journal of Supply Chain Management, Management Science) and identified the primary data analysis techniques used in each article. A total of 283 of 405 articles were published utilising various quantitative and qualitative techniques, although the largest percentage was advanced quantitative techniques such as regression, factor analysis, structural equation modelling (SEM), and ANOVA. Similarly, in a study by Sachan and Datta (2005), the authors found that survey methods were the most widely used methodology (34\%), followed by case studies (16\%), mathematical modelling (10\%), interviews $(7 \%)$, conceptual modelling $(6 \%)$, simulation $(5 \%)$, and all others $(23 \%)$.

The theoretical aspects of SCM research is examined later in this article, but suffice to say that there have been few studies that have attempted to develop theories of the supply chain. Pagell and Wu (2009) utilized a qualitative methodology (e.g. case studies) to build a theory of sustainable SCM. The authors include social and environmental outcomes, and specific "green" initiatives taken by members of supply chains to develop their theory. Interestingly, their analysis suggested that the most sustainable supply chains combine best practices and "new" behaviours. Essentially, firms in a supply chain must innovate beyond existing best practices.

Li et al. (2005) conceptualized and validated six dimensions of SCM practices, including strategic supplier partnerships, customer relationships, information sharing, information quality, internal lean practices, and postponement of operations or activities. SEM was used to test and validate the measures used and which could assist other researchers examining the performance of supply chains. The authors also expressed hope that their research would facilitate SCM theory development and additional empirical studies using their measurement constructs.

Manuj et al. (2009) presented an 8-step simulation model development process for the design, implementation, and evaluation of logistics and supply chain simulation models. The authors emphasized the importance of rigor in the use of simulation models so that other researchers and practitioners would have more trust in the results. Similarly, Blackhurst et al. (2005) developed a methodology — Product Chain Decision Model (PCDM) 
- that models the supply chain and includs consideration of the product and manufacturing process design. As part of their discussion of their methodology, the authors briefly discussed other modelling techniques that were used to examine supply chains, including optimisation and pure modelling. Other recent modelling attempts included Roghanian et al. (2007) and Yang, et al. (2009). Peidro et al. (2009) provided a summary of the more than 100 references from 1988 to 2007 to works where supply chain models were proposed. It is an excellent reference for researchers attempting to gain perspectives on SCM modelling.

One of the major differences between traditional research and investigation of supply chains is that there are more firms involved in the supply chain. As a result, the use of dyads and triads are more valuable approaches to studying supply chain relationships. Unfortunately, such research is even more difficult when the number of "partners" increases. Most models of the supply chain, such as the SCOR model, examine a portion of the supply chain. SCOR includes a focal firm, its suppliers' supplier, its supplier, the customer, and the customers' customer (Supply Chain Council, 2009). The inclusion of five separate organisational entities goes beyond the simple dyad or even triad. It is certainly possible to examine triads and beyond quantitatively, but the logistics of trying to get multiple firms to participate in a supply chain project involving all partners is very difficult. Choi and $\mathrm{Wu}(2009)$ are some of the few authors who have attempted to examine triadic relationships. They explored buyer-supplier-supplier relationships within the supply chain and developed nine triadic archetypes of relationships. The authors also utilised theories from other disciplines in their research, including balance theory from behavioural psychology and the structural-hole concept from the social network literature.

Bonett and Wright (2009) employed a very traditional analytical method, confidence intervals, to examine various supply chain and operations research issues. The authors argued that hypothesis tests we often misinterpreted. They identified what they perceived as the weaknesses of hypothesis testing and recommended that confidence intervals be used instead, primarily because of the increased amount of information that they provide the researcher. Several examples of SCM issues were presented, including: (1) purchasingsupplier relationships; (2) usage of concurrent engineering and computer aided design, and satisfaction with suppliers; (3) level of supply chain integration; (4) use of JIT inventory strategy in the supply chain; and (5) use of causal models or structural equation models in SCM research.

\subsection{Developing solutions or answers to specific supply chain-related problems or challenges}

There are a myriad of issues facing supply chain practitioners where research is being conducted to aid them in making optimal decisions. The issues of coordination, collaboration, integration, technology implementation, and information availability are examples of key issues that are being explored by SCM researchers.

To illustrate, it is commonly accepted that accurate and timely information availability allows supply chain decision makers to make better decisions. However, most decisions made by supply chain executives are made with incomplete information. Cantor and Macdon- 
ald (2009) examined two types of decision-making or problem solving — abstract problem solving; and concrete problem solving - to determine which approach worked best when executives were faced with limited or questionable information. The authors found that the abstract approach worked best with limited information. As more and better information become available, either problem solving approach would work. Similarly, Hsu et al. (2008) investigated the effects of information sharing capability on buyer-supplier relationships and firm performance. Using regression analysis, the authors found a positive relationship between these variables.

Within this perspective, some researchers have examined the relationships of various activities and processes on supply chain performance, which is an important topic of interest to practitioners. As an example of this research, Schwarz \& Weng (2000) evaluated the effect of lead-time uncertainty on safety stock in the design of a JIT supply chain. The authors combined modelling case study approaches to conclude that there were significant interactions between relevant components of the supply chain, so when designing the optimal supply chain, management should not focus on any single component to the exclusion of others. If they did, the trade-offs must be recognized, measured, and responded to in some meaningful way.

One of the key issues facing organisations today is supply chain disruption. There are many internal and external factors that contribute to the risks facing firms. Often, these risks have a low probability, but significant negative impacts if they occur; and they often occur suddenly and without much warning. Many authors have examined supply chain disruptions and the strategies required to successfully manage such risk (Manuj and Mentzer, 2008; Paulsson, 2004; Wagner and Bode, 2008). One particular research study by Braunscheidel and Suresh (2009) examined the ability of organisations to be agile with respect to supply chain risk. The authors utilised SEM to determine that supply chain agility was highly and positively correlated to three organisational practices: internal integration, external integration with key suppliers and customers, and external flexibility. Impacting these three practices are the firm's market orientation (e.g. customer orientation, competitor orientation, inter-functional coordination) and learning orientation (e.g. commitment to learning, shared vision, open-mindedness).

There are many other very specific issues that impact supply chain executives which researchers have also investigated. Nadler and Kros (2008) examined legal issues that impact supply chains, specifically the Sarbanes-Oxley Act. Galbreth et al. (2008) investigated cross-docking in a variety of supply chain environments. Rodrigues et al. (2008) developed a supply chain uncertainty model that explicitly included transportation along with suppliers and customers. White et al. (2008) examined RFID in the supply chain. The authors discussed the results of RFID implementation by European early adopters for organisations considering this technology. Dröge and Germain (2000) examined an important component of SCM, logistics, using LISREL modelling, and found that EDI was positively related to both inventory and financial performance. When demand was stable, firms were small, and when JIT was used, the relationship was especially strong. Finally, Bhatnagar and Teo (2009) incorporated key decision issues, such as complexities of extended supply chains and the coordination of transportation, inventory, information and facilities, in the mathematical modelling of the global supply chain. The authors iden- 
tified three key challenges to successful global coordination of the supply chain, namely non-stationary demand, variability propagation, and inventory imbalances.

\subsection{Measuring results or outcomes of supply chain strategies/tactics}

An issue of significant importance to supply chain practitioners and researchers is how and what to measure relative to the outputs of the supply chain. And, while it is intuitive that effective and efficient SCM should result in improvements in firm and supply chain performance, there is little empirical support for this notion.

Stank et al. (2001) utilised a survey of CSCMP members to ascertain whether the performance of firms was due, in part, to the extent that supply chain members were involved in collaborative efforts. Factor analysis and SEM were utilized to test their hypotheses. The authors found that collaboration, both internal and external, were associated with higher levels of service performance. Nakano (2009) also used SEM to examine performance in the supply chain. Within a Japanese setting, the author specifically examined the impact of internal and external collaborative forecasting and planning on logistics and production performance; two key components of SCM. He found a positive relationship between internal and external collaborative forecasting and planning, both upstream and downstream in the supply chain, as well as internal collaborative forecasting and planning. They all had positive effects on logistics and production performance.

Bozarth et al. (2009) developed a model of supply chain complexity to determine the impacts of various types of complexity on supply chain performance. Using the manufacturing plant as a setting, the authors found that complexity (upstream, manufacturing, or downstream) had a negative impact on performance. As part of their discussion, they identified 12 measures of supply chain complexity; such as average product life cycle, number of products produced, and number of suppliers to the manufacturing plant; which would affect performance.

Barber (2008) utilized the balanced scorecard method to measure the performance of the supply chain as a whole. The author's framework included both tangible and intangible elements that impact supply chain success, including participant satisfaction, financial management, strategic management, change management, relationship management, and quality, innovation and knowledge management. Barber suggested that additional research would help to identify key performance indicators of these constructs.

As a general point, since the final customer is the ultimate focus of the supply chain, it would be reasonable to assume that the same or similar elements of customer satisfaction should be important. Irrespective of whether a traditional channel of distribution exists, or whether or not the supply chain is highly integrated or fragmented, the final customer primarily "sees" the outputs of the system. Therefore, logic might imply that more traditional elements, such as on-time delivery, high product quality, complete and accurate product information, competitive prices, and other measures of satisfaction, would also be useful elements to measure relative to supply chain performance. This issue is, however, still being debated by practitioners and researchers, and is an area of potential exploration in the future. 


\section{Topics for exploration}

Given the breadth and scope of SCM, there are an almost endless number of topics that could be researched. The topics are so numerous and varied that researchers can address the issues from almost any background or perspective that they choose. Behavioural researchers can examine relationships of supply chain partners or the role of consumers in SCM strategies. Modellers can model the entire supply chain, portions of the chain, or individual components. There is still a great need to examine traditional topics such as transportation, warehousing, inventory management, and others, but from a supply chain perspective rather than an individual firm's orientation. In the discussion that follows, some potential areas of research exploration are presented. The areas are twofold: theory development, and SCM processes and functions. The topics presented are not meant to be an exhaustive list of possible research areas, but are perceived by this author to be those that can offer the greatest long-term potential for advancing the body of SCM knowledge.

Frankel et al. (2008) provided an overview of the development of SCM from the perspectives of many of its key disciplines or elements: purchasing, operations management, logistics, and marketing channels of distribution. The authors identified the defining of SCM, domain of SCM, SCM's topics of interest, SCM's unit and level of analysis, and theory and methodology, as important areas for investigation by SCM researchers. Other researchers have called for additional SCM-related research as well (Burgess et al. 2006). Similarly, Mentzer et al. (2008) identified future research implications resulting from a better understanding of SCM and logistics, marketing, production, and operations management.

\subsection{Theory development}

Theory development includes the precise definition of terms or constructs, identifying the breadth and scope of SCM, and identifying what theories, principles, approaches and methodologies could be applied to SCM from other disciplines. Many researchers have called for more theory development in SCM. Mentzer et al. (2001) commented that a management construct cannot be used effectively if there was no agreement on what it meant. The authors examined various definitions of SCM and identified three major components of a SCM framework: management philosophy, a set of activities to implement a management philosophy, and a set of management processes. Each of the components could be distinct perspectives for expanding SCM-related research.

As an example of research that has attempted to define supply chain constructs more precisely, Chen et al. (2009) attempted to define and operationalise a key aspect of SCM, namely supply chain integration. The authors proposed a two-faceted approach to defining the construct: internal supply chain process integration, and external supply chain process integration. Furthermore, the two facets could be broken down into two dimensions: connectivity, and simplification. Each dimension could then be examined by researchers. Similarly, Zokaei and Hines (2007) attempted to explicitly define supply chain effectiveness and supply chain efficiency. Since these are two terms that are foundational to measuring the performance of supply chains, specific definitions are important to SCM theory development. 
Stock $(1996,1997)$ advocated the application of theories, principles, methodologies, and approaches from non-logistics and non-SCM disciplines to the examination of SCM-related issues. He identified numerous theories from non-business disciplines that could have potential application in logistics and SCM. In his study, Stock utilised a resource book published by Bothamley (1993) which identified over 4000 theories, laws, hypotheses, principles, rules and theorems, from a multiplicity of disciplines. The reference, while dated somewhat, still provides a fertile resource for SCM researchers trying to identify relevant thought from non-business that might apply to SCM-related research.

During the decade since Stock published his articles, many researchers have "borrowed" from other disciplines as they approached their own SCM-related research. For example, Fawcett et al. (2008) utilised contingency and force field theories from organisational behaviour to develop a model of supply chain coordination. Grimm (2008) discussed the influence of economics on SCM and specifically examined empirical methods and economic theories (e.g. mathematical models, structure-conduct-performance paradigm, transaction cost theory, resource-based view, dynamic capability theory, evolutionary economics, competitive dynamics). Min et al. (2008) borrowed social identity and social capital theory from psychology and sociology to explore the notion of social capital in supply chains. Carter and Rogers (2007) explored the concept of sustainability from economics and environmental management and applied it within a supply chain context.

Additionally, Skipper et al. (2008) explored the coordination aspects of SCM by using organisational behaviour theories to study the issue. The authors utilised coordination theory and interdependence theory, in combination with the supply chain constructs of coordination, interdependence and technologies, to identify technology-enabled coordination strategies. A significant contribution of this research study was to identify eight theoretical propositions that could be examined which could expand the body of knowledge relating to interdependence, coordination and technologies in SCM. With respect to suppliers, vendors, manufacturers and retailers, it is well accepted that good relationships between organisations is positively correlated to higher performing supply chains. Cousins et al. (2006) examined the relationship strength and quality among buying and supplying organisations. They employed SEM to expand on theoretical models of group behaviour and relationships, and applied them to SCM.

From the perspective of general theory development, Wacker (2008) provided some guidance to developing sound theory in SCM. The author identified the requirements of "good" theory and presented a checklist for supply chain researchers for developing SCM theories. Hunt (1976) also presented a comprehensive approach towards the development of theory in marketing, which can easily be adapted for use by research exploring theoretical issues in SCM.

As examples of the type of research that attempts to develop general theories of SCM, Lejeune and Yakova (2005) proposed a typology for configuring supply chains. They identified four configurations: communicative, coordinated, collaborative and co-opetitive. In developing their typology or taxonomy, the authors conducted a literature review of published research dealing with defining SCM and specifying its components. Based on the premise that there were different supply chain forms, the authors used several criteria to develop their typology, including: type of inter-functional integration employed, type of 
issues faced, type of modelling techniques used, methodology used, type of product, and level or stages of supply chain integration.

Theoretical constructs have also been investigated by researchers, although much more can be accomplished in this area. For example, the notion of postponement is an important aspect of SCM. Boone et al. (2007) examined the notion of postponement in the supply chain. The authors performed an extensive literature review to determine the progress of postponement thought and theory. Using Van Hoek's (2001) five areas of potential postponement research, Boone et al. elaborated on the opportunities within each area: (1) postponement as a supply chain concept, (2) integrating related supply chain concepts, (3) relating postponement to the globalisation of supply chains, (4) postponement in the customized supply chain, and (5) methodological upgrading of postponement.

\subsection{SCM processes and functions}

As mentioned earlier, there are many existing studies that have examined traditional logistics topics such as transportation, warehousing, inventory management, customer service, information technology and others. Within other areas that are directly or indirectly linked to SCM - such as marketing, finance, information systems and others - there are traditional topics - such as channels of distribution, branding, product development, activity based costing and data warehousing - that have previously been investigated by researchers, but not from a SCM perspective. These traditional topics and areas of research should be re-examined in view of the expanded context of SCM.

In a special issue of the Journal of Operations Management published in 2005, Forza et al. (2005) summarized the published SCM-related articles and identified general areas of research opportunities. According to the authors, the opportunities included: "(1) the introduction of greater complexity into the coordinating approaches by considering other decision variables or parameters ... relaxing model constraints, changing the nature of the decision variables from deterministic to stochastic, etc., (2) replication studies that seek to improve the generalisability of reported findings, and (3) research going beyond numerical examples that use empirical data to asses the applicability and efficacy of the various proposed coordinating approaches" (Forza et al. 2005, p. 322).

Certainly, the defining of constructs and the creation of basic SCM models are foundational to the development of the discipline. These basic models can then be expanded to include additional complexity. There are a number of basic supply chain models that have been proposed over the last decade, such as SCOR and the Forum model. The SCOR model, which has been the focus of the majority of SCM researchers, includes five components plan, source, make, deliver, and return - has been used by several researchers to formulate models of the supply chain. The Supply Chain Council, which includes practitioners, academicians and consultants, has done a reasonably thorough job of identifying the basic components of the supply chain and evaluates the supply chain from the perspective of four levels of analysis: process types (plan, source, make deliver, return); process categories (types of processes, such as planning, execution, enable); decompose processes (definitions, source of inputs and outputs, performance metrics, best practices); and decompose process elements (i.e. implementation). 
Other researchers have developed models independent of the SCOR model, such as the Forum model (Cooper et al. 1997). Unfortunately, multiple, independent modelling attempts do not lend themselves to developing synergy; that is, a SCM model that can be used by other researchers to build upon what has been done before. These models are often derived in isolation with little replication and expansion by other researchers. Often, they are not specific enough to be "tested" by others, because they are mostly descriptive and difficult to operationalise.

Regarding other aspects of SCM, most researchers and practitioners would agree that excellent supply chain strategies and operations result from good collaboration, coordination and integration. There have been some research attempts to examine behavioural issues in the supply chain. Certainly, there are consumer behaviour issues that could be addressed, but also those behavioural issues relating to supplier collaboration and coordination, such as creating and maintaining strategic partnerships and alliances. Even the very specific issues, such as contract negotiation with various suppliers, vendors and third-party service providers, have behavioural implications associated with them.

With the increasing interest in sustainability and energy, some authors have begun to examine these topics, but much more still needs to be done. As an example of research that could be conducted, Zinn and Liu (2001) utilised a multinomial logit model to examine 24 independent variables related to consumer responses to product stockouts. The authors found that situational factors had a significant impact on consumer perceptions and responses. With the environmental issues of clean air, increasing energy prices and/or the reduced availability of fossil fuels, "green" marketing, and many others becoming more important to consumers, companies and governments, research into the sustainable supply chain is much needed.

There are a myriad of potential topics that SCM researchers could explore. In addition to those mentioned above, other topics that would benefit from additional research include: supply chain structures and organisational issues, global procurement and sourcing, demand forecasting, government regulation and its impact on the supply chain, outsourcing options, technology adoption and implementation (e.g. RFID, wireless, GPS, pick-tolight), lean manufacturing and logistics, developing and maintaining agile systems, and establishing performance metrics, measures and key performance indicators.

\section{A concluding comment}

The scope and breadth of SCM-related research is increasing, but there are still numerous opportunities available to extend and enrich what is known about supply chains. There are opportunities to expand the theoretical foundations of the SCM discipline and to provide research which assists supply chain executives to address and solve problems. Research on the newer challenges associated with planning, implementing and controlling SCM strategies and tactics is needed. Additionally, replication of some of the research that has already been conducted will help to reinforce basic concepts of the discipline. The future is indeed very positive with respect to researchers being able to provide practitioners and academicians with meaningful and synergistic SCM-related research. 


\section{References}

[1] Autry C \& GRIFFis S, 2008, Supply chain capital: The impact of structural and relational linkages on firm execution and innovation, Journal of Business Logistics, 29(1), pp. 157-173.

[2] BArber E, 2008, How to measure the "value" in value chains, International Journal of Physical Distribution \& Logistics Management, 38(9), pp. 685-698.

[3] Bhatnagar R \& Teo C-C, 2009, Role of logistics in enhancing competitive advantage: A value chain framework for global supply chains, International Journal of Physical Distribution \& Logistics Management, 39(3), pp. 202-226.

[4] Blackhurst J, Wu T \& O'Grady P, 2005, PCDM: A decision support modeling methodology for supply chain, product and process design decisions, Journal of Operations Management, 23(4), pp. 325-343.

[5] Bonett D \& Wright T, 2009, Using confidence intervals in supply chain and operations research, Journal of Supply Chain Management, 45(1), pp. 26-33.

[6] Boone C, Craighead C \& Hanna J, 2007, Postponement: An evolving supply chain concept, International Journal of Physical Distribution \& Logistics Management, 37(8), pp. 594-611.

[7] Bothamley J, 1993, Dictionary of theories, Gale Research International Ltd., London.

[8] Boyer K \& Swink M, 2006, Editorial, Journal of Operations Management, 24(6), pp. 731-733.

[9] Bozarth C, Warsing D, Flynn B \& Flynn E, 2009, The impact of supply chain complexity on manufacturing plant performance, Journal of Operations Management, 27(1), pp. 78-93.

[10] Braunscheidel M \& Suresh N, 2009, The organizational antecedents of a firm's supply chain agility for risk mitigation and response, Journal of Operations Management, 27(2), pp. 119-140.

[11] Burgess K, Singh P \& Koroglu R, 2006, Supply chain management: A Structured literature review and implications for future research, International Journal of Operations \& Production Management, 26(7), pp. 703-729.

[12] Cantor D \& Macdonald J, 2009, Decision-making in the supply chain: Examining problem solving approaches and information availability, Journal of Operations Management, 27(3), pp. 220-232.

[13] CArter C \& Rogers D, 2007, A framework of sustainable supply chain management: Moving toward new theory, International Journal of Physical Distribution \& Logistics Management, 38(5), pp. 360-387.

[14] Charvet F, Cooper M \& Gardner J, 2008, The intellectual structure of supply chain management: A bibliometric approach, Journal of Business Logistics, 29(1), pp. 47-73.

[15] Chen H, Daugherty P \& Roath A, 2009, Defining and operationalizing supply chain process integration, Journal of Business Logistics, 30(1), pp. 63-84.

[16] Chог T \& Wu Z, 2009, Triads in supply networks: Theorizing buyer-supplier-supplier relationships, Journal of Supply Chain Management, 45(1), pp. 8-25.

[17] Cooper M, Lambert D \& PaGH J, 1997, Supply chain management: More than a new name for logistics, The International Journal of Logistics Management, 8(1), pp. 1-14.

[18] Council of Supply Chain Management Professionals, 2009, Definition of supply chain management, [Cited on July 15 th , 2009], [Online], Available from http://www.cscmp.org.

[19] Cousins P, Handfield R, Lawson B \& Petersen K, 2006, Creating supply chain relational capital: The impact of formal and informal socialization processes, Journal of Operations Management, 24(6), pp. 851-863.

[20] Dooley K, 2009, The empiricism-modeling dichotomy in operations and supply chain management, Journal of Supply Chain Management, 45(1), pp. 38-43.

[21] Dröge C \& Germain R, 2000, The relationship of electronic data interchange with inventory and financial performance, Journal of Business Logistics, 21(2), pp. 209-230.

[22] Fawcett S, Magnan G \& McCarter M, 2008, A three-stage implementation model for supply chain collaboration, Journal of Business Logistics, 29(1), pp. 93-112.

[23] Forza C, Salvador F \& Rungtusanatham M, 2005, Coordinating product design, process design, and supply chain decisions - Part B: Coordinating approaches, tradeoffs, and future research directions, Journal of Operations Management, 23(4), pp. 319-324. 
[24] Frankel R, Bolumole Y, Eltantawy R, Paulraj A \& Gundlach G, 2008, The domain and scope of SCM's foundational disciplines - Insights and issues to advance research, Journal of Business Logistics, 29(1), pp. 1-30.

[25] Giunipero L, Hooker R, Joseph-Matthews S, Yoon T \& Brudvig S, 2008, A decade of SCM literature: Past, present and future implications, Journal of Supply Chain Management, 44(4), pp. 66-86.

[26] GRIMm C, 2008, The application of industrial organization economics to supply chain management research, Journal of Supply Chain Management, 44(3), pp. 16-21.

[27] Hsu C-C, KANNAN V, TAN K-C \& LEONG G, 2008, Information sharing, buyer-supplier relationships, and firm performance: A multi-region analysis, International Journal of Physical Distribution \& Logistics Management, 38(4), pp. 296-310.

[28] Hunt S, 1976, Marketing theory: Conceptual foundations of research in marketing, Grid, Inc, Columbus $(\mathrm{OH})$.

[29] LAseter T \& Oliver K, 2003, When will supply chain management grow up? Strategy + Business, Reprint No. 03304, [Cited on July 15 $5^{\text {th }}$ 2009], [Online], Available from http://www. strategy-business.com/press/16635507/03304.

[30] Lejeune M \& Yakova N, 2005, On characterizing the 4 C's in supply chain management, Journal of Operations Management, 23(1), pp. 81-100.

[31] Li S, Rao S, Ragu-Nathan T \& Ragu-Nathan B, 2005, Development and validation of a measurement instrument for studying supply chain practices, Journal of Operations Management, 23(6), pp. 618-641.

[32] Manuj I \& Mentzer J, 2008, Global supply chain risk management, Journal of Business Logistics, 29(1), pp. 133-155.

[33] Manuj I, Mentzer J \& Bowers M, 2009, Improving the rigor of discrete-event simulation in logistics and supply chain research, International Journal of Physical Distribution \& Logistics Management, 39(3), pp. 172-201.

[34] Menachof D, Gibson B, Hanna J \& Whiteing A, 2009, An analysis of the value of supply chain management periodicals, International Journal of Physical Distribution \& Logistics Management, 39(2), pp. 145-166.

[35] Mentzer J, DeWitt W, Keebler J, Min S, Nix N, Smith C \& Zacharia Z, 2001, Defining supply chain management, Journal of Business Logistics, 22(2), pp. 1-25.

[36] Mentzer J, Stank T \& Esper T, 2008, Supply chain management and its relationship to logistics, marketing, production, and operations management, Journal of Business Logistics, 29(1), pp. 31-46.

[37] Min S, Kim S \& Chen H, 2008, Developing social identity and social capital for supply chain management, Journal of Business Logistics, 29(1), pp. 283-304.

[38] NaKano M, 2009, Collaborative forecasting and planning in supply chains: The impact on performance in Japanese manufacturers, International Journal of Physical Distribution \& Logistics Management, 39(2), pp. 84-105.

[39] Pagell M \& Wu Z, 2009, Building a more complete theory of sustainable supply chain management using case studies of 10 exemplars, Journal of Supply Chain Management, 45(2), pp. 37-56.

[40] Paulsson U, 2004, Supply chain risk management, pp. 79-96 in BRIndley C (Ed), Supply chain risk, Ashgate Publishing Limited, Hampshire.

[41] Peidro D, Mula J, Poler R \& Lario F-C, 2009, Quantitative models for supply chain planning under uncertainty: A review, International Journal of Advanced Manufacturing Technology, 43(3/4), pp. $400-420$.

[42] Rodrigues V, Stantchev D, Potter, A, Naim M \& Whiteing A, 2008, Establishing a transport operation focused uncertainty model for the supply chain, International Journal of Physical Distribution \& Logistics Management, 38(5), pp. 388-411.

[43] Roghanian E, Sadjadi S \& Aryanezhad M, 2007, A probabilistic bi-level linear multi-objective programming problem to supply chain planning, Applied Mathematics \& Computation, 188(1), pp. $786-800$.

[44] Sachan A \& DatTa S, 2005, Review of supply chain management and logistics research, International Journal of Physical Distribution \& Logistics Management, 35(9), pp. 664-705. 
[45] SANDERs N, 2009, Bridging the gap between methodological camps in supply chain management, Journal of Supply Chain Management, 45(1), pp. 49-51.

[46] Schwarz L \& Weng Z, 2000, The design of a JIT supply chain: The effect of leadtime uncertainty on safety stock, Journal of Business Logistics, 21(2), pp. 231-253.

[47] Skipper J, Craighead C, Byrd T \& Rainer R, 2008, Towards a theoretical foundation of supply network interdependence and technology-enabled coordination strategies, International Journal of Physical Distribution \& Logistics Management, 38(1), pp. 39-56.

[48] Stank T, Keller S \& DAugherty P, 2001, Supply chain collaboration and logistical service performance, Journal of Business Logistics, 22(1), pp. 29-48.

[49] Sтоск J, 1997, Applying theories from other disciplines to logistics, International Journal of Physical Distribution \& Logistics Management, 27(9/10), pp. 515-539.

[50] Sтоск J, 1996, The social sciences and logistics: Some suggestions for future research, Journal of Marketing Theory and Practice, 4(2), pp. 1-25.

[51] Sтоск J \& Boyer S, 2009, Developing a consensus definition of supply chain management: A qualitative study, International Journal of Physical Distribution \& Logistics Management, 39(8), pp. 690-711.

[52] Supply Chain Council, 2009, Supply-chain operations reference-model, Version 9.0, [Online], [Cited on August $\left.1^{\text {st }}, 2009\right]$, Available from http://www.supply-chain.org.

[53] WACKeR J, 2008, A conceptual understanding of requirements for theory-building research: Guidelines for scientific theory building, Journal of Supply Chain Management, 44(3), pp. 5-15.

[54] WaGner S \& Bode C, 2008, An empirical examination of supply chain performance along several dimensions of risk, Journal of Business Logistics, 29(1), pp. 307-325.

[55] White A, Johnson M \& Wilson H, 2008, RFID in the supply chain: Lessons from European early adopters, International Journal of Physical Distribution \& Logistics Management, 38(2), pp. 88-107.

[56] Yang G, Wang Z \& Li X, 2009, The optimization of the closed-loop supply chain network, Transportation Research: Part E, 45(1), pp. 16-28.

[57] Zinn W \& LiU P, 2001, Consumer response to retail stockouts, Journal of Business Logistics, 22(1), pp. $49-71$.

[58] ZokAei K \& Hines P, 2007, Achieving consumer focus in supply chains, International Journal of Physical Distribution \& Logistics Management, 37(3), pp. 223-247. 